\title{
BANHEIRO REQUEER: PROTOCOLO TEATRAL VERBO-VISUAL EM DISCURSO
}

\author{
Dr. Jean Carlos Gonçalves ${ }^{1}$ \\ jeancarllos@ufpr.br
}

Ms. Reinaldo Kovalski de Araujo ${ }^{2}$

rei.rka.rka@gmail.com

O presente artigo é resultado de uma pesquisa de mestrado, realizada no programa de pós-graduação em educação (PPGE) da Universidade Federal do Paraná (UFPR). A pesquisa lança um olhar sobre os sentidos produzidos sobre gênero, corpo e identidades por professoras de teatro durante a montagem de um espetáculo teatral, em um projeto de formação continuada.

As professoras $^{3}$ participantes dessa pesquisa integram o projeto de investigação A Construção das Identificações de Gênero no Espaço Cênico (Faculdade de Artes do Paraná,) e tem por objetivo discutir as contribuições do teatro na construção das subjetividades dos corpos, especialmente no ambiente educacional. A proposta dos encontros é contribuir para o aprofundamento das reflexões sobre

\footnotetext{
${ }^{1}$ Doutor em Educação pela Universidade Federal do Paraná (PPGE/UFPR), com estágio de pós-doutorado em Linguística Aplicada e Estudos da Linguagem na Pontifícia Universidade Católica de São Paulo (LAEL/PUC-SP, supervisão de Beth Brait). Licenciado e Bacharel em Teatro-Interpretação e Mestre em Educação pela Universidade Regional de Blumenau (FURB). Professor Adjunto da UFPR, atuando na graduação em Produção Cênica e nos Programas de Pós-Graduação em Educação (PPGE - Mestrado Acadêmico e Doutorado) e Educação: Teoria e Prática de Ensino (PPGE:TPEn - Mestrado Profissional). Líder do grupo de pesquisa ELiTe - Laboratório de estudos em Educação, Linguagem e Teatro (UFPR/CNPq).

${ }^{2}$ Mestre em Educação pela Universidade Federal do Paraná (PPGE/UFPR), Licenciado em Teatro pela Faculdade de Artes do Paraná (FAP). Integrante do grupo de pesquisa ELiTe - Laboratório de estudos em Educação, Linguagem e Teatro (UFPR/CNPq).

${ }^{3}$ Um aspecto a ser considerado nessa pesquisa é a opção por utilizar o sujeito feminino quando esse não for definido. Historicamente construímos no processo da escrita uma invisibilidade do sujeito feminino ao determinarmos sempre o masculino. As referências a: "os alunos", "os professores", "os educadores" mostram como a linguagem também está inserida em um mecanismo de discurso que estabelece lugares para a dicotomia de gênero. Ainda na esteira da preocupação de algumas teóricas como Judit Butler, que em nome de uma visibilidade utiliza os conceitos de "as/os", opto por utilizar o substantivo feminino na preocupação de possibilitar uma agradável leitura e, ao mesmo tempo, algum estranhamento. Compreendo essa ação como também geradora de padrões e hierarquizações de gênero, mas lanço essa escolha como um processo de discussão e possibilidades. Revista "O Teatro Transcende" Departamento de Artes - CCEAL da FURB - ISSN 2236-6644 - Blumenau, Vol. 20, № 1, p. 38 -52, 2015
} 
processos de discriminação, de exclusão social, de evasão escolar ocasionada por discursos biológicos e reprodutivos, definidores de papéis e de comportamentos sociais, de gênero e sexuais.

O projeto mesclou professoras com diversos níveis de experiência na docência. Os encontros culminaram na produção de um espetáculo teatral que dialogou com as questões de corpo, gênero e diversidade sexual, a partir da Teoria Queer. O espetáculo teve como título REQUEER.

Os autores que pautaram a discussão sobre os conceitos de gênero e sexualidades desse projeto foram BUTLER (2003), FOUCAULT (2001), LOURO (2004). A partir dos conceitos propostos pelos autores, e das leituras em grupos, as envolvidas no processo de trabalho foram inseridas nos estudos de gênero, categoria que orientou, posteriormente, a montagem das cenas.

O trabalho de concepção do espetáculo se concretizou a partir de uma linha contemporânea de encenação, onde o foco são os processos investigativos do corpo. Nesse sentido, o texto aparece a partir dos trabalhos corporais vivenciados pelas atrizes na prática, dando particular ênfase na investigação das ações físicas e corporais. As teorias e metodologias que orientam essa prática de fazer teatral partem dos trabalhos cênicos desenvolvidos por Vsevolod Meyerhold, Antonin Artaud, Eugenio Barba, Peter Brook, Ingrid Koudela e Viola Spolin.

As discussões iniciais se deram a partir da Teoria Queer em especial com a leitura de Problemas de Gênero. Feminismo e subversão da identidade de BUTLER (2003). Em diálogos propostos pela autora com as ideias de FOUCAULT (2001) sobre a construção da sexualidade na modernidade e pós-modernidade, as professoras começaram a compreender as questões de gênero e sexualidade, de modo a transcender os binarismos sexuais até então presentes, inclusive dentro do pensamento feminista adotado por algumas integrantes do grupo. 
A proposta da montagem de REQUEER busca um olhar para as relações entre o feminino e o masculino para além de uma formação biológica ou somente social e histórica. A construção do conceito de gênero e identidade é trabalhada a partir de possibilidades discursivas passíveis de estetização, de modo que "podemos entender que a sexualidade envolve rituais, linguagens, fantasias, representações, símbolos, convenções, processos profundamente culturais e plurais." (LOURO, 2001. Pg. 63)

Para as reflexões desse artigo utilizamos os enunciados produzidos por uma professora a partir dos protocolos de construção do espetáculo na perspectiva da verbo-visualidade. Para tanto, apresentamos a concepção de protocolo teatral, e protocolo teatral verbo-visual.

\section{DO PROTOCOLO TEATRAL AO PROTOCOLO TEATRAL VERBO-VISUAL}

O trabalho com os protocolos é uma prática utilizada por professoras de teatro para avaliação e reflexão de processo criativo. Como durante as aulas de teatro o corpo é usado como forma de expressão, impossibilitando paradas para tomadas de notas reflexivas e escritas, o protocolo realizado após o final de um processo ou sessão auxilia no registro das experiências ali abordadas, tornando material aquela vivencia (KOUDELA, 2006). Os protocolos carregam em si a materialidade de uma vivência particular efêmera da experiência teatral. Partem de escritas, desenhos, colagens, gravações, e demais recursos que falam sobre aquele processo:

A cada sessão, um aluno diferente ou um grupo de alunos se responsabiliza pela confecção do protocolo referente aos assuntos discutidos, aos episódios ocorridos e às reflexões sobre os trabalhos daquele dia. (...) Explica-se aos estudantes que podem utilizar colagens, desenhos, fotos, imagens, adesivos, etc. na confecção de seus protocolos. (JAPIASSU, 2001, pg. 53) 
Para essa pesquisa os protocolos foram construídos na perspectiva verbovisual, fundamentação teórico-metodológica de construção de corpus na pesquisa em teatro-educação proposta por GONÇALVES (2013a), elaborada a partir dos estudos sobre a verbo-visualidade propostos por Brait (2012):

O termo verbo-visual implica, necessariamente, um enunciado concreto no qual as dimensões verbal e visual sejam indissociáveis, o verbal e o visual possuem, na dimensão verbo-visual, um lugar que não permite separação, nem valoração de um em detrimento de outro. Ambos são necessários à compreensão do enunciado em seu todo (GONÇALVES, 2013a. pg. 111)

Os protocolos teatrais verbo-visuais são possibilidades metodológicas para discussão e avaliação do processo, e também de construção do corpus de análise desse trabalho, compreendendo-se este como coleção finita de dados selecionados para a pesquisa (BAUER e GASKELL, 2002).

Nessa perspectiva, foi solicitado às professoras integrantes do grupo, que ao final de todo o processo elaborassem um protocolo na perspectiva da verbovisualidade, que materializasse, de certo modo, a vivencia cênica ali experimentada. $\mathrm{A}$ proposta não era dar conta de todo acontecimento e vivência artística, mas possibilitar fragmentos que apontasse para sentidos produzidos por essa experiência. O enunciado que norteou a montagem dos protocolos foi: "o que ficou em mim dessa experiência de formação?"

O objetivo da análise é a interrogação sobre os sentidos, e não o conteúdo dos protocolos. Estes, que não são traduzidos, mas produzidos pelos sujeitos na elaboração desse processo, são intercalados e mediados pela ideologia, pela linguagem e pela historia de cada uma das professoras.

Vale destacar que a pesquisa considera a posição dos sujeitos e o lugar de onde eles falam, que nesse caso se constitui de um grupo de professoras de teatro que participaram de uma formação continuada, culminando na montagem de um 
espetáculo teatral que discutiu questões que envolvem gênero, corpo, sexualidades e identidade na perspectiva da Teoria Queer.

\section{DA SELEÇÃO E ANÁLISE DOS DADOS}

A partir da Análise do Discurso de linha francesa (AD), ensaiamos possibilidades de investigação de um dos protocolos confeccionados. Para esse artigo foi selecionado o protocolo Banheiro. Este consiste em uma instalação artística montada dentro de um banheiro público por uma das professoras. A escolha por esse protocolo se dá na medida em que o espaço do banheiro é delimitador dos binarismos de gênero, fornecendo materialidades que produzem sentidos e nos levam a questionar os espaços destinados ao masculino e ao feminino.

Para tal análise, compreendo que ao interpretar um discurso imagético/verbal imprimo um possível vestígio de olhar, situado em um lugar próprio ideológico definido pelo meu contexto sócio e histórico (ORLANDI, 2013), o que não descarta outras possibilidades de sentidos, logo que estamos falando de trabalho artístico.

A intenção não é revelar nenhuma verdade sobre o sujeito e sim trabalhar com os sentidos do seu discurso, que é marcado pela heterogenia da sua historia e ideologia "nada há por trás das cortinas, nem sob o chão que pisamos. Há enunciados e relações, que o próprio discurso põe em funcionamento. Analisar o discurso seria dar conta exatamente disso: de relações históricas, de práticas muito concretas, que estão vivas. nos discursos" (FISCHER, 2001, p 22).

\section{PROTOCOLO TEATRAL VERBO-VISUAL - BANHEIRO}

O protocolo "Banheiro" consiste em um conjunto de imagens, escritas e objetos postos, colados, e distribuídos dentro do espaço do banheiro. A maioria das imagens 
utilizadas são imagens impressas por impressora digital em folha branca. As escritas são em sua maioria digitais, acompanhadas de poucas manuscritas.

A professora utiliza, para a montagem de seu protocolo, textos verbais (escritos e musicais) trabalhados durante a montagem do espetáculo e textos visuais (imagéticos, retirados da internet, objetos do seu trabalho cotidiano e fotos pessoais), o que remete a uma escrita de si (o que ficou em $\mathrm{mim}$ ) em diálogo com seu contexto, utilizando as escritas que a cercam para apresentar uma concepção pessoal sobre os assuntos discutidos durante a montagem do espetáculo.

De acordo com as concepções de PÊCHEUX (2009), o sujeito que fala é antes de tudo um misto das concepções que permeiam a língua e a historia. Por não ter o domínio absoluto dos fatores que compõem seu discurso, ele não é totalmente livre, o discurso para se materializar precisa da ilusão da autoria ou esquecimento ideológico, entendidos como a ilusão de que somos a origem do que dizemos, e que o que dizemos significa exatamente o que queremos (ORLANDI, 2013).

Nesse sentido, o sujeito não tem a autoria plena desse discurso, logo que é atravessado pela historia, pela sua posição social e pelo lugar de onde fala. Porém, essa ilusão autoral não pode ser vista como algo negativo ou como apagamento do sujeito. Ela é condição indispensável para produção discursiva, logo que é a partir dessa tomada inconsciente que o sujeito produz sentidos, e posteriormente materializa seu discurso.

Foucault nos ajuda a entender esse sujeito que não é total, único e centrado, mas ao contrário é múltiplo. A ideia do falante se desdobra em muitas outras: qual o status do enunciador? Que lugar ocupa? Qual o seu campo de saber? Qual sua posição dentro da instituição? Qual sua relação com a hierarquia ali estabelecida? Por que escolheu aquelas imagens, textos e local para apresentar seu protocolo? 
Não pretendemos esgotar, neste artigo, todos esses questionamentos. Nosso intuito é convidar o leitor, a partir de alguns apontamentos, a pensar na pluralidade de sentidos possíveis de serem produzidos na materialidade de um protocolo verbovisual.

A escolha da linguagem da instalação como possibilidade para apresentação de um protocolo teatral remete a uma filiação contemporânea com a concepção da arte. O trabalho permite a exploração de uma percepção corporal, característica das vanguardas que fluíram a partir da década de 60 . O protocolo convida a participação física da observadora, ele não é somente para ser visto, é para ser experimentado, vivenciado, adentrado. Essa concepção de protocolo faz muito sentido para sua análise, pois ele se faz na relação com o interlocutor.

A escolha do banheiro como "lugar de exposição" nos remete aos ínfimos lugares em que o discurso artístico pode fazer sentido, desestabilizando os locais sacralizados para apreciação de produtos e obras de arte, levando ao extremo os suportes, configurando outras possibilidades de se ver e se fazer arte.

O banheiro pode ser compreendido como o lugar da intimidade do corpo, o lugar em que os olhares externos não alcançam, uma possível ilusão do "canto escuro" do Panótipo (FOUCAULT, 2007). Em uma sociedade em que o corpo carrega seus tabus e sua forma hegemônica de representação, o banheiro pode se situar como o espaço possível de transgressões. Considerando as ideias de BARBOSA (1984), podemos compreender que o escrito, feito ou desenhado nos banheiros, não faz parte da discussão aberta da sociedade.

O banheiro, ao mesmo tempo, é um espaço de transgressão e, também, cabine de vigilância de gênero, limitador e afirmador de dicotomias masculinas e femininas (PRECIADO, 2002). Antes mesmo de adentrá-lo, já somos questionados sobre nossa configuração de gênero, nos obrigando a selecionar o corpo capaz de ocupar aquele 
espaço. Entramos no banheiro não somente para expelir excrementos; adentramos nesse espaço também para afirmar nossa identidade de gênero.

As textualidades verbo-visuais da instalação foram aqui separadas em 3 formações imaginárias: Meu reflexo no espelho, corpos (des) construídos e o lugar da escola. Vale destacar que essa divisão didática se faz a partir da interpretação dos pesquisadores, e que os sentidos que permeiam corpo, gênero e sexualidade encontram-se imbricados em ambas as formações.

\section{MEU REFLEXO NO ESPELHO}

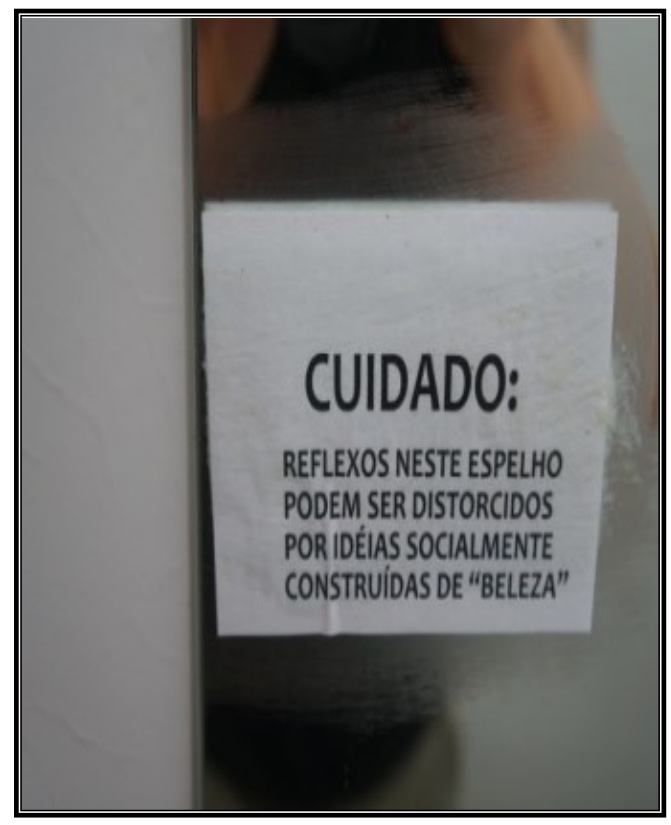

Figura 1 - Autor: Reinaldo K. Araujo

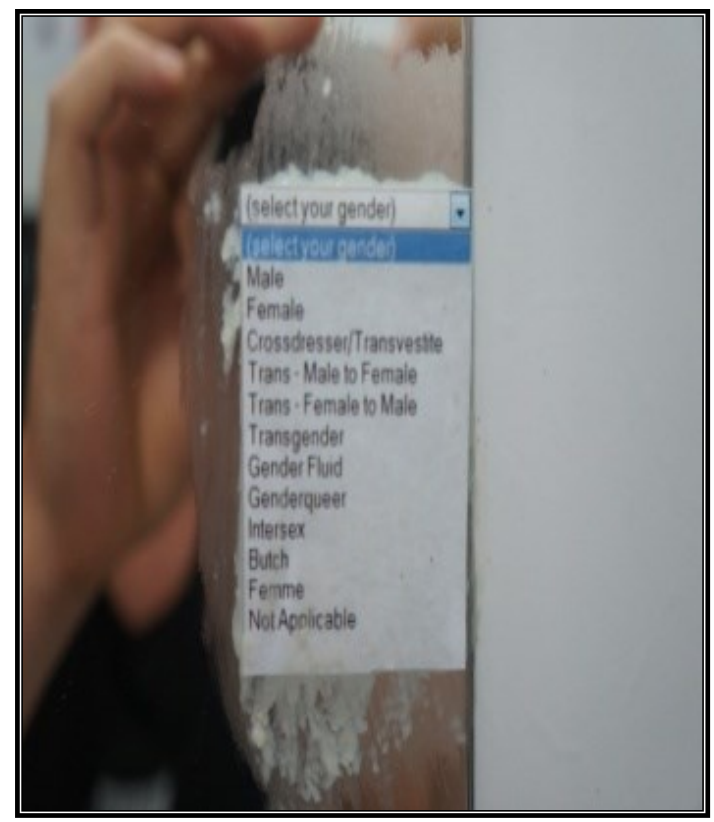

Figura 2 - Autor: Reinaldo K. Araujo

Os enunciados verbais contidos na FIGURA 1 e FIGURA 2 estão colados no espelho do banheiro, e possuem uma relação entre si, pois necessitam da imagem do espelho para se constituírem em uma relação de verbo-visualidade, a partir do reflexo do interlocutor. 
As subjetividades dos corpos fazem sentido nas imagens acima selecionadas, e a professora/artista nos convida por meio do espelho a questionar nossa própria construção identitária. As imagens verbo-visuais refletidas no espelho questionam como eu me identifico dentro das opções de gênero socialmente construídas. Os sentidos propostos dialogam com as idéias de BUTLER (2003) sobre as questões referentes à formação das identidades e das subjetividades, e nos convidam a pensar sobre os processos pelos quais nos tornamos sujeitos ao assumir (no caso da figura, selecionar) identidades sexuais dentro de capturas legitimadas pela hegemonia heterossexual.

Vale destacar que as opções selecionadas para o sujeito que "olha no espelho" não partem de um binarismo - homem/mulher -, mas apontam para outras construções de subjetividades (FIGURA 2): crossdresser, travesti, trans - male to female, trans female to male, transgender, genderfluid, genderqueer, intersex, butch, femme, incluindo aberturas para outras ainda não categorizadas como na frase "not aplicable"${ }^{4}$.

Os sentidos apontados pela professora/artista sobre as questões de identidade se ampliam quando na obra, não demarca o banheiro como espaço binário, mas o transforma em uma possibilidade de habitação de múltiplas identidades.

\section{CORPOS (DES) CONSTRUÍDOS}

A seqüência de imagens a seguir afirma o espaço daquele banheiro como possível de habitação das múltiplas formas de expressão de gênero, sexualidades e construções corporais:

4As partes em inglês que compõem a obra da professora apontam para uma escrita de si, logo que a autora viveu um determinado tempo nos Estados Unidos. Revista "O Teatro Transcende" Departamento de Artes - CCEAL da FURB - ISSN 2236-6644 - Blumenau, Vol. 20, No 1, p. 38 -52, 2015 


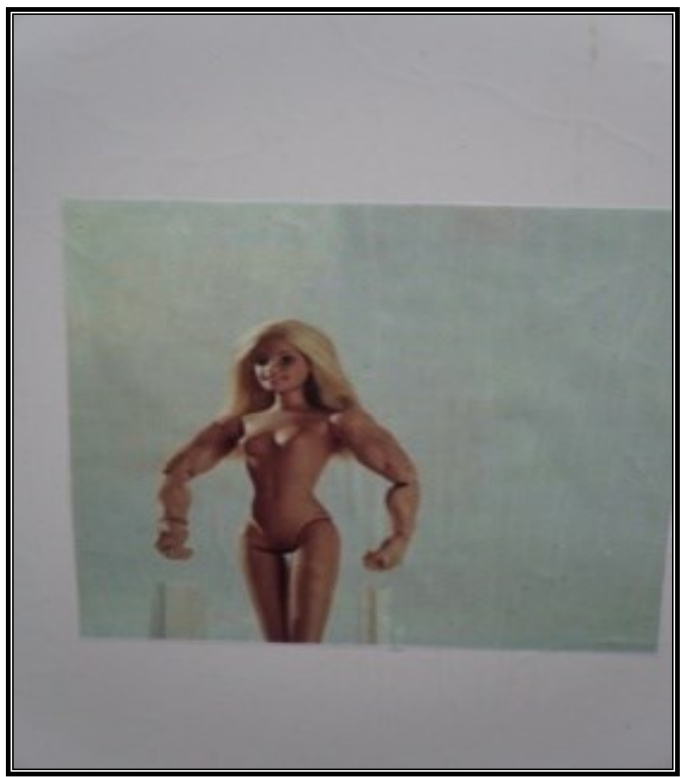

Figura 3 - Autor: reinaldo k. Araujo

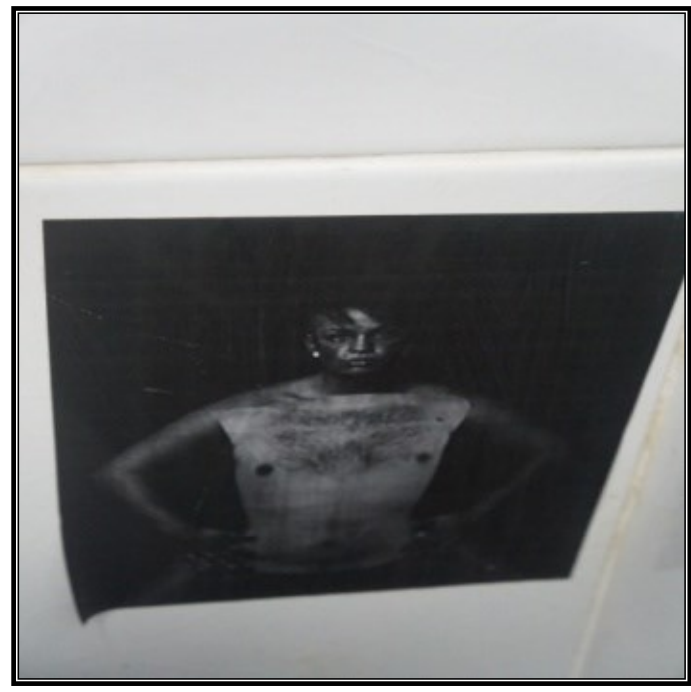

Figura 5 - Autor: Reinaldo K. Araujo

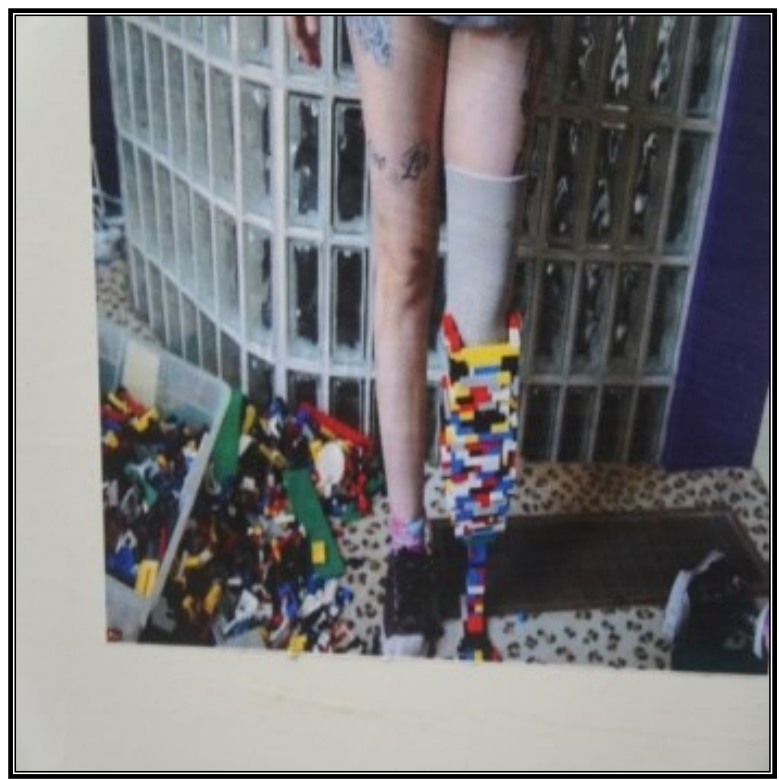

Figura 4 - Autor: Reinaldo K. Araujo

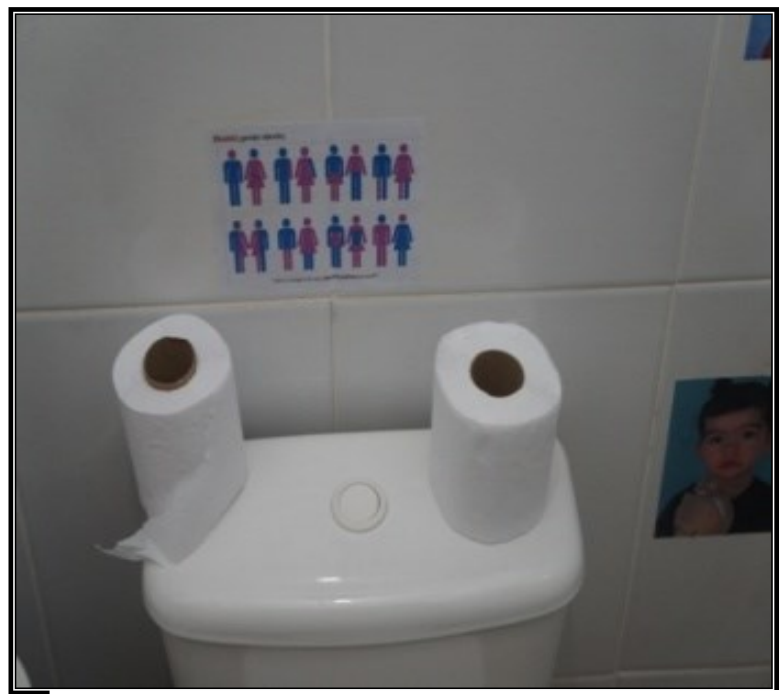

Figura 6 - Autor: Reinaldo K. Araujo

As Figuras 3, 4, 5 e 6 são textos verbo-visuais que representam possibilidades de outras identidades e arranjos corporais (Figuras 3,4,5) e afetivos (Figura 6). Ao olhar para o espelho nos deparamos com nossa imagem, com as imagens acima, e com o texto colado sobre o espelho compondo o enunciado verbo-visual (a imagem refletida + as imagens das fotos coladas + o enunciado verbal = quem sou eu?) 
Ao mesmo tempo em que o espelho questiona pela escrita verbal qual identidade devemos escolher em uma "caixa de expansão" ${ }^{5}$, as imagens de outras possibilidades de corpos rompem com o binarismo de gênero e com as concepções padrões de elaboração dos corpos, desconstruindo o conceito de beleza, de harmonia corporal e de normalidade na formação de um corpo/sexo/gênero.

O espelho também nos adverte sobre a possibilidade de tudo o que vemos ali refletido serem distorções, influenciadas pelas óticas sociais que imprimo ao apreciar o trabalho. Nesse sentido, a instalação realiza uma meta crítica, e se propõe a não achar respostas para as questões ali colocadas, mas nos convida a repensar os sentidos que aquele contexto pode produzir.

\section{O LUGAR DA ESCOLA.}

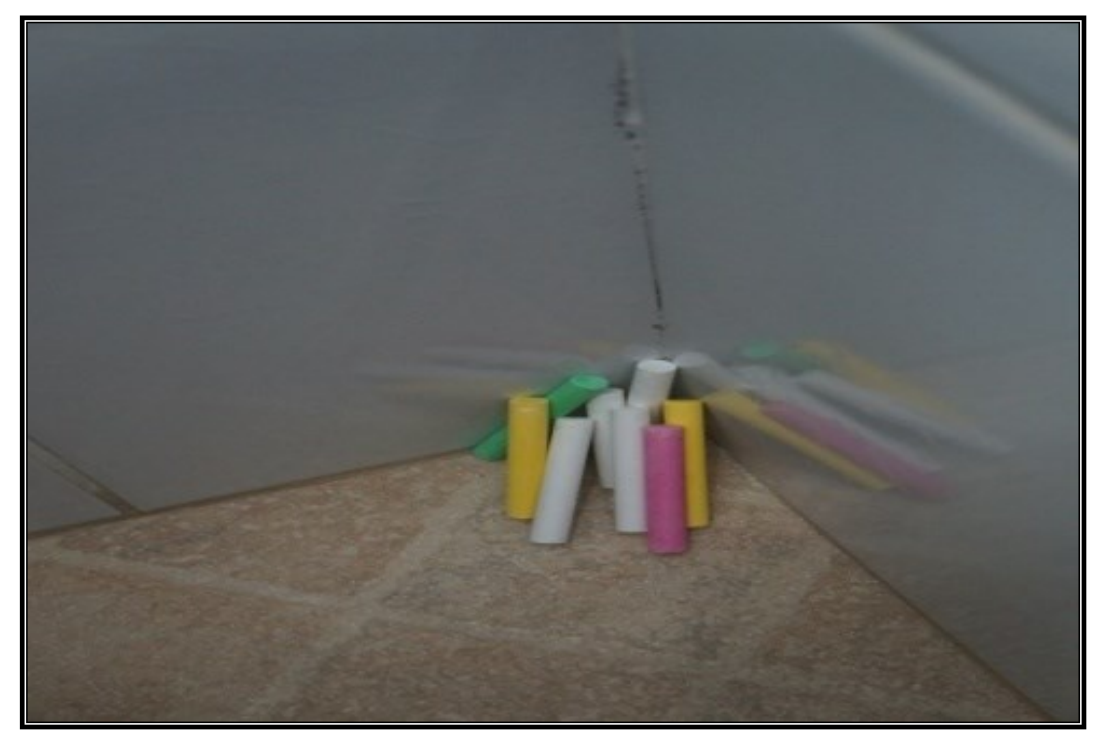

Figura 7 - Autor: Reinaldo K. Araujo

O objeto tridimensional "giz colorido" (FIGURA 7) é colocado no canto do banheiro. A relação de sentido que esse objeto produz nos aponta para o lugar da educação na discussão de gênero.

\footnotetext{
${ }^{5}$ Uma referência ao ambiente virtual do computador, onde as opções já estão delimitadas, e prontas para serem selecionadas, e direcionadas para outros hiperlinks. 
Vale destacar que o espaço produzido pela professora/artista remete a uma zona de possibilidades de construção de identidades, porém o elemento giz, único referente à escola, encontra-se em um canto, não captado pelo reflexo do espelho e quase sem relação com as identidades ali dadas como possíveis.

O giz naquele espaço construído é quase como um corpo estranho; ele não dialoga com o sujeito do espelho, e nem com as imagens corporais ali existentes, embora se constitua como elemento essencial para a produção de sentidos em perspectiva verbo-visual. Ele existe quase que separado das relações de sentido de todos aqueles objetos. Assim é necessário compreender a função da escola dentro de um contexto disciplinador, onde discursos são produzidos na tentativa de construção de corpos dóceis, dentro de uma inteligibilidade governamental (FOUCAULT, 2007).

A questão que se desdobra a partir dos sentidos produzidos pela obra é: como a escola dialoga com as múltiplas identidades do sujeito, sendo essa uma instituição que ainda trabalha no âmbito do controle e da ordenação dos corpos? Quais os sentidos que a escola produz para um corpo fora dos padrões vigentes de corpogênero-sexualidade?

Para concluir, compreendemos o protocolo teatral verbo-visual banheiro como uma materialidade discursiva capaz de produzir sentidos múltiplos sobre os conceitos de corpo, gênero e sexualidade; e aponta para a compreensão de um corpo possível de transgressão, não fixo e aberto para possibilidades de existência.

O enunciado proposto pela professora/artista permite ver as questões de gênero e sexualidade, para além de uma discussão sobre feminino, misoginia ou violência contra a mulher, tão presente nos discursos escolares sobre sexualidade e gênero. O convite que se faz é o de adentrar em um espaço não binário, pensar possibilidades de existência que não estão condicionadas aos binômios homem/mulher, mas um pensar Queer sobre existência. 
O trabalho questiona e em nenhum momento aponta certezas, o que caracteriza um olhar para as questões de gênero que ultrapassa as fronteiras das explicações biológicas, se permitindo interrogações e questionamentos, não se fechando em uma explicação, mas se abrindo para múltiplas leituras.

Por fim, esclarecemos que outras leituras devam ser feitas a partir desse trabalho, como por exemplo: relações entre subjetividades construídas dentro e fora do armário/banheiro, relação entre o interior e o exterior dos espaços de afirmação de gênero, a naturalização dos corpos pela biologia, a arte como propositora de discurso sobre gênero e diversidade sexual, etc. Apesar de não terem sido aprofundadas nessa análise, essas questões têm presença significativa nesses discursos.

\section{REFERÊNCIAS:}

BARBOSA, Gustavo. Grafitos de banheiro. São Paulo: Brasilense, 1984.

BAUER, M; GASKELL, G. Pesquisa qualitativa com texto, imagem e som: um manual prático. Petrópolis: Vozes, 2002.

BRAIT, Beth. Construção coletiva da perspectiva dialógica: história e alcance teóricometodológico. In: FIGARO, Roseli. Comunicação e Análise do Discurso. São Paulo: Contexto, 2012.

BRITZMAN, Debora. In O corpo Educado. Pedagogias da Sexualidade. Org. Guacira Lopes Louro. Belo Horizonte: Autêntica, 2003

BUTLER, Judith. Problemas de gênero. Feminismo e subversão da identidade. Rio de Janeiro: Civilização Brasileira, 2003. 
FISCHER, Rosa Maria Bueno. Foucault e a análise do discurso em educação. Cadernosde Pesquisa, São Paulo: Fundação Carlos Chagas/Editores Associados, n. 1, jul. 2001, p.197-223.

FOUCAULT, Michel. História da sexualidade I: a vontade de saber.Rio de Janeiro: Graal, 2001.

. Michel. Vigiar e Punir: história da violência nas prisões. Petrópolis, Rio de Janeiro: Vozes, 2007.

GONÇALVES, Jean Carlos. Protocolos teatrais verbo-visuais: produção de sentidos para a prática teatral universitária. Bakhtiniana. Revista de Estudos do Discurso. PUCSP: São Paulo, 2013.

O corpo no teatro: reflexões bakhtinianas a partir de protocolos teatrais verbo-visuais. In: Revista Polifonia, v. 20, n. 27. UFMT: Cuiabá, 2013. p. 229-250.

JAPIASSU, R. Metodologia do ensino do teatro. Campinas: Papirus, 2001.

KOUDELA, I. Jogos teatrais. São Paulo: Perspectiva, 2006.

LOURO. Currículo, gênero e sexualidade - O "normal", o "diferente" e o "excêntrico". In: LOURO, Guacira Lopes; NECKEL, Jane Felipe; GOELLNER, Silvana Vilodre. (Orgs.) Corpo, gênero e sexualidade: um debate contemporâneo na educação. Petrópolis: Vozes, 2003.

Um corpo estranho. Ensaios sobre sexualidade e teoria queer. Belo Horizonte: Autêntica, 2004.

O Corpo educado: pedagogias da sexualidade. 2ed. Belo Horizonte:

Autêntica, 2001. 
MARTINS, Guaraci da Silva Lopes. Encontro marcado: um trabalho pedagógico com performances teatrais para a discussão das sexualidades em espaços de educação. Tese de Doutorado. UFBA. 2009

ORLANDI. Eni P. Análise do discurso: princípios e procedimentos. 11 ed. Campinas, SP. Pontes. 2013.

PÊCHEUX, M. Semântica e Discurso. Tradução de EniPulcinelliOrlandi. Campinas: Editora da UNICAMP, 2009.

PRECIADO, Beatriz. Basura y Género, Mear/Cagar. Masculino/Femenino. Bilbao: Amasté, 2002.

SPARGO, Tamsin. Foucault y la Teoria Queer. Tradução GrabielaVantureira. Barelona: Gedisa S.A. 1999. 